\title{
Enfermedad perianal tratada como acné conglobata como debut de enfermedad de Crohn
}

\author{
M. Barreales, A. Laluezaํ, M. Manzano, C. González¹ y J. A. Solís Herruzo \\ Servicio de Medicina Aparato Digestivo $y^{\prime}$ Medicina Interna. Hospital Universitario 12 de Octubre. Madrid
}

\section{CASO CLÍNICO}

Varón de 40 años en seguimiento por el Servicio de Dermatología por presentar lesiones nodulares glúteas dolorosas, con drenaje purulento. Fue diagnosticado histológicamente de foliculitis quística profunda supurativa, compatible con acné conglobata, con cultivo positivo para Staphylococcus aureus. Recibió tratamiento con prednisona (15 mg/día), isotetricina y rifampicina sin mejoría. Además, asociaba un cuadro de un año de evolución de pérdida de $25 \mathrm{~kg}$ de peso y dolor abdominal, con aparición de fiebre en las últimas semanas. El paciente fue remitido para ingreso. A la exploración física estaba caquéctico, y presentaba en la región glútea y perianal múltiples lesiones nodulares con zonas cicatriciales entre ellas, que drenaban material purulento (Fig. 1). En la analítica destacaba una anemia ferropénica grave (Hb: 7,2 g/dl), aumento de los reactantes de fase aguda (PCR:13) y datos de malnutrición (albúmina: 2,49 g/dl, colesterol: 8,3 mg/dl). Se realizó una colonoscopia observando pseudopólipos, úlceras y un aspecto mucoso en empedrado en recto y colon transverso, así como dos orificios fistulosos; el diagnóstico histológico fue de enfermedad inflamatoria intestinal tipo enfermedad de Crohn (EC). En una RMN pélvica se visualizó una fístula perianal izquierda con extensión a raíz de muslo izquierdo (Fig. 2). Se pautó tratamiento con esteroides a dosis altas, 5-ASA, antibióticos y azatioprina, con una notable mejoría clínica, analítica y la práctica resolución de las lesiones cutáneas (Fig. 3). En este caso la existencia de otro diagnóstico (acné conglobata) junto con la presentación de la EC como enfermedad perianal (EPA) llevó a un retraso en el diagnóstico, lo cual pudo ser determinante en el desarrollo de estas graves lesiones.

\section{DISCUSIÓN}

La EPA en una manifestación frecuente de la EC con una morbilidad significativa, como la incontinencia fecal y la proctectomía (10-18\%) (1). La incidencia acumulada de EPA en la EC varía entre el 14-38\% (2,3). Schwartz y cols. encontraron una incidencia acumulada de EPA del $21 \%$, y un $45 \%$ de los casos desarrollaron fístulas antes o en el momento

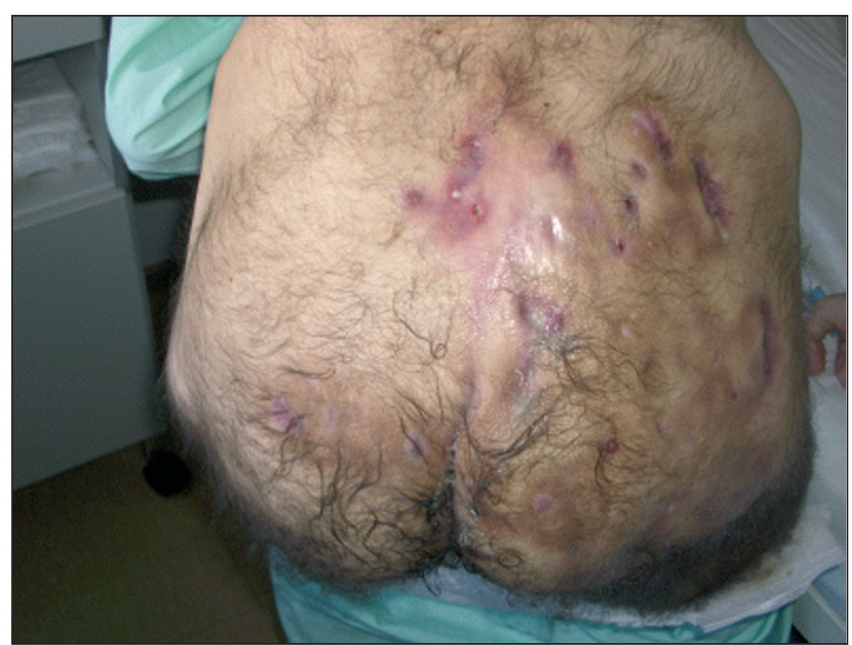

Fig. 1. Región glútea con múltiples lesiones modulares y zonas cicatriciales.

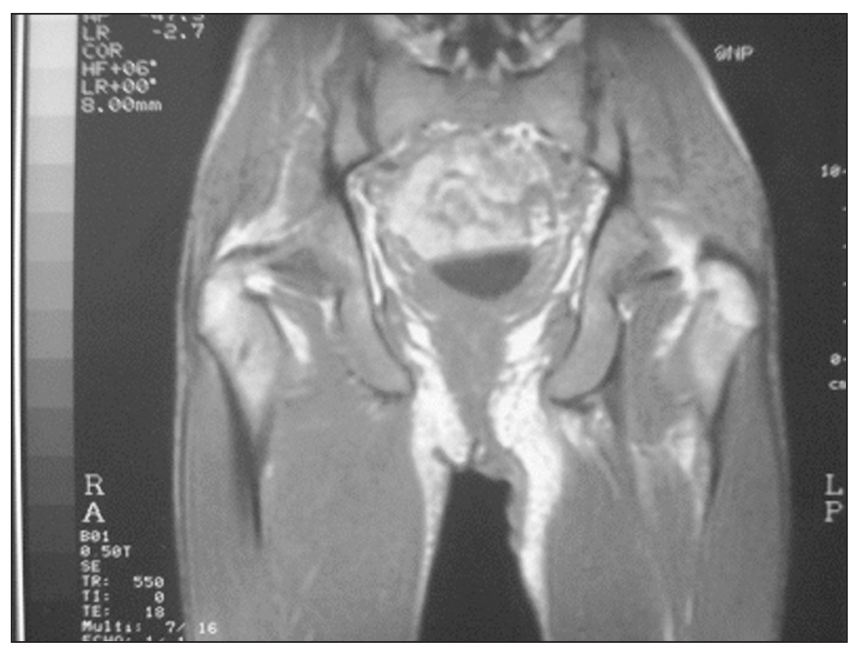

Fig. 2. RMN: se observa una fístula perianal izquierda con extensión a raíz de muslo izquierdo. 


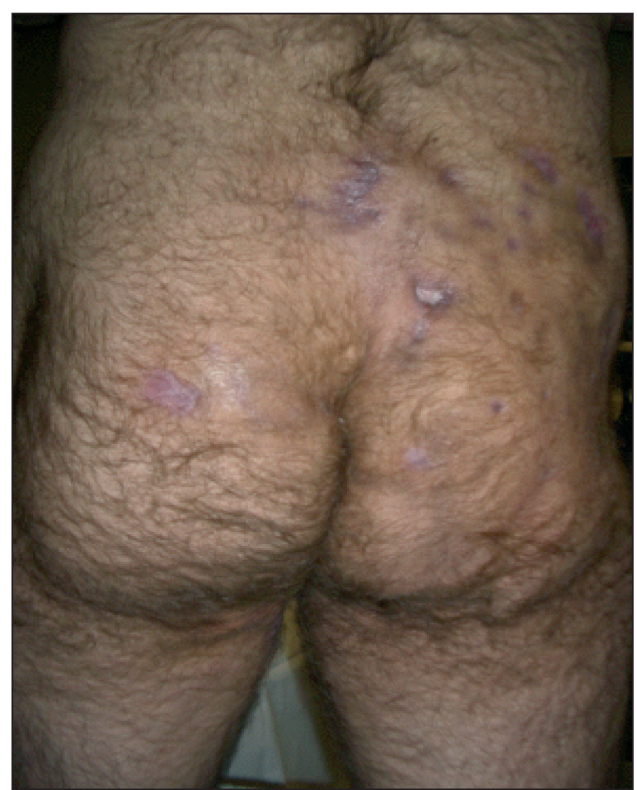

Fig. 3. Evolución de las lesiones tras tratamiento a una fase cicatricial no supurativa. farmacológicas disponibles para el manejo de la EPA y del incremento de su eficacia, en ocasiones se debe recurrir a un manejo conjunto médico-quirúrgico (1-3). del diagnóstico, lo que subraya la dificultad del diagnóstico de EC en pacientes que sólo se presentan con EPA $(1,4)$. Para su evaluación y diagnóstico se debe partir de un alto índice de sospecha y realizar una cuidadosa exploración perianal, seguido de una rectoscopia para evaluar la existencia de actividad inflamatoria rectal. El estudio debe completarse con una RMN pélvica o una ecografía endoanal, que recientemente han demostrado su alta rentabilidad diagnóstica en la clasificación de las fístulas, o incluso con una exploración bajo anestesia que, realizada por un cirujano experto, es la técnica diagnóstica más fiable. Combinando dos de estos tres procedimientos se obtiene un diagnóstico correcto en el $100 \%$ de los casos $(2,3)$. Con respecto al tratamiento médico, es fundamental tener en cuenta la presencia de sintomatología, la existencia o no de proctitis y la complejidad anatómica de las fístulas. En los pacientes sintomáticos con afectación rectal debe pautarse tratamiento específico tópico o sistémico (esteroides y 5-ASA). Los antibióticos han demostrado eficacia en el tratamiento de la EPA en estudios no controlados, fundamentalmente metronidazol y ciprofloxacino, obteniéndose los mejores resultados cuando se emplean estos de forma combinada. Tras suspender el tratamiento la recidiva es precoz, por lo que se tiende a asociar diversos inmunosupresores, entre los que destacan la azatioprina y la 6-mercaptopurina, que han demostrado su eficacia en cinco estudios controlados. Finalmente, en los casos de EPA refractaria al tratamiento convencional puede ser necesario recurrir al infliximab. No obstante, a pesar de las opciones terapéuticas

\section{BIBLIOGRAFÍA}

1. Schwartz DA, Herdman CR. Review article: the medical treatment of Crohn's perianal fistulas. Aliment Pharmacol Ther 2004 ; 19 : 953-67.

2. AGA technical review on perianal Crohn's disease. Gastroenterol 2003; 125: 1508-30.

3. Mendoza JL, Taxonera C, Lana R, Alba C, García-Paredes J, Díaz-Rubio M. Recomendaciones en el manejo diagnóstico y terapéutico de la enfermedad de Crohn fistulosa perianal. Rev Esp Enferm Dig 2005; 97: 46-56.

4. Schwartz D, Loftus E, Tremaine W, Panaccione R, Sandborn W. The natural history of fistulizing Crohn's disease: a population based study. Gastroenterology 2000; 118(4): A337. 